\title{
Vantagens de uma gramática de usos para o Português Europeu. Alguns exemplos de análise de expressões extraídas de usos orais informais
}

\author{
Isabel Margarida Duarte \\ Universidade do Porto
}

\begin{abstract}
:
Taking into account the theoretical assumptions that praise the description of the use of the system and not only of the system in abstract, we will defend the need for a grammar of uses for European Portuguese. Such a description implies dealing with the complexity, the gradualness of linguistic phenomena, the compulsory contextualization of discourses, both in discursive genres and in their enunciative circumstances. This description testifies that regularities also exist in use and there should not be an excessive cut between describing the language and describing the use of language. Unlike what happens in Brazilian Portuguese, in European Portuguese there are few researches that focus on these uses, and even less researches that deal with oral productions, namely interactional and informal, based on corpora. It is necessary to pay more attention to the uses, above all to the description of the functioning of the language as discourse updated in certain discursive genres, as the informal conversation. These studies are crucial both for the teaching of Portuguese as a foreign language and as a mother tongue, since describing only the system, the standard variety, generally written, is scientifically reductive and ineffective from the point of view of teaching. But descriptions of uses are also essential for translation studies or contrastive analyzes of both different languages and different varieties of Portuguese. Starting from small research experiences that take place with university students, we propose a research route with corpora of familiar conversations, which try to account for the unguarded oral uses of the language, in an interaction context. Finally, two examples of this working plan will be advanced: that of the presentational marker "é assim" and that of the vague nominal quantifiers, with a function of attenuation and diminution of the speaker's enunciative responsibility, "Um bocado = a bit" and "Um bocadinho $=$ a little." We will conclude by showing how the corpora analysis of informal conversations even allows us to better understand some characteristics of literary texts.
\end{abstract}

Keywords: uses, informal conversation, European Portuguese

Palavras-chave: usos, oral informal, Português Europeu

\section{Introdução}

Os objetivos deste texto são os seguintes: (1) defender a necessidade de uma gramática de usos para o Português Europeu (PE); (2) apresentar um percurso de investigação baseado nos estudos dos usos da língua, experimentado com estudantes; (3) exemplificar, com duas estruturas presentes em conversas informais, o género de questões que podem ser descritas e as vantagens dessa descrição.

Eis o plano que iremos seguir: na Introdução, serão expostos alguns pressupostos teóricos, sendo adiantados motivos, uns de tipo teórico e outros de tipo empírico, que nos levam a defender a descrição dos usos. Posteriormente, será apresentado um percurso de investigação, atento aos usos e à variação, experimentado com estudantes de mestrado, sendo justificadas algumas opções metodológicas e fornecidos exemplos práticos. Os exemplos limitar-se-ão ao marcador apresentador "é assim", aos quantificadores "um 
bocado" / "um bocadinho" e à consideração de várias estratégias discursivas que, em simultâneo, concorrem para um mesmo efeito de sentido. Serão, por último, feitas algumas considerações finais.

São múltiplas, dentro da Linguística, as correntes que descrevem os usos do sistema e não o sistema em abstrato, desligado das condições reais da sua utilização. Mas essas orientações teóricas que estudam o uso, "os produtos verbais efectivamente actualizados" (Fonseca, 1994: 96), defendendo que «uma língua enquanto sistema é indissociável da sua função comunicativa» (Matos 2008: 391), não produziram ainda, no caso do Português Europeu, uma descrição dos usos da língua consistente e alargada, com resultados em número suficiente, contrariamente ao que acontece no Brasil, por exemplo, onde houve mais atenção dos linguistas aos usos, sobretudo aos orais, como atestam, entre outros estudos, o manual de gramática da autoria de Maria Helena Moura Neves $(2000)^{1}$, mas também toda a extensa produção teórica em torno do projeto $\mathrm{NURC}^{2}$. A obra de Maria Helena Moura Neves "mostra como está sendo usada a língua portuguesa atualmente no Brasil" (Neves 2000: 13), para os estudar e sistematizar. O facto de uma gramática deste tipo partir do estudo de usos atestados e vivos vai implicar a consulta de corpora e não pode ser construída na base da intuição do linguista ou de exemplos por ele forjados. Por cá, existe ainda espaço para alargar o número de trabalhos, baseados em corpora, que se debruçam sobre os usos da língua sobretudo em produções orais, nomeadamente interacionais e informais ${ }^{3}$, sendo, em contrapartida, já mais estudados os discursos dos media, a publicidade, os discursos parlamentar e político em geral, e mais utilizados corpora escritos, p.e., de discurso jornalístico, como o CETEMpublico. Se correntes como a análise conversacional, a linguística interacionista e a análise do discurso têm, em Portugal, feito um trabalho assinalável, não tomaram ainda suficientemente em consideração, na maior parte dos casos, unidades típicas das interações familiares informais. Tendo em conta o ponto da situação feito por Johnen (2012: 309), haveria que congregar esforços no sentido de avançar com investigação em algumas áreas possíveis de análise, de interface entre semântica e pragmática, ou sintaxe e pragmática, etc., já que o elenco das descrições existentes, realizado pelo autor, confirma a sua escassez. A organização e disponibilização de corpora de conversas informais é um instrumento indispensável para esta análise e descrição dos usos que urge levar a cabo.

\subsection{Pressupostos teóricos}

Exporemos, brevemente, algumas convicções teóricas que respaldam o nosso trabalho e nas quais ele se enquadra. Defendemos a vantagem de estudar exemplos atestados em corpora e não apenas criados pelo investigador. No caso destes últimos, há, por vezes, uma adaptação do protótipo à teoria explicativa que o investigador defende, sendo os exemplos de aceitabilidade duvidosa no uso, embora até possam ser, por vezes, gramaticais ${ }^{4}$.

A atenção ao uso e a consideração do sistema não são contraditórias nem irreconciliáveis, muito pelo contrário, como já defendeu Fonseca (1992, 1994), de forma convincente, nos inícios dos anos 90. Usamos a língua, que é um sistema, mas usamo-la de modo frequentemente diferente e bem mais complexo do que o previsto na forma como ela é descrita nas gramáticas. Como escreveu Óscar Lopes, nós raramente falamos

\footnotetext{
${ }^{1}$ Também a gramática de Azeredo (2008), não sendo uma gramática de usos, revela uma atenção muito especial a eles.

${ }^{2}$ Projeto de Estudo da Norma Urbana Linguística Culta do Brasil.

${ }^{3}$ Basta analisarmos a gramática da Fundação Gulbenkian (2013), para verificarmos como continua a faltar-nos um estudo sistemático dos usos efetivos da língua em diversas situações, apesar de esta gramática apresentar já alguns capítulos em que as abonações são retiradas de corpora.

${ }^{4}$ Dois exemplos que Joana Batalha (2017: 107) cita na sua tese de doutoramento, aliás excelente, ilustram o que pretendo dizer. Há ocorrências de frases gramaticias que nos parecem estranhas e que ninguém diria e há exemplos agramaticais que seriam usados assim na oralidade informal. Os critérios de aceitabilidade e adequação discursiva não são os mesmos da gramaticalidade: "O cavalo [que o cão mordeu [-]] saltou por cima do porco.", sendo gramatical não é, provavelmente, um enunciado frequente do português. Já "*O jogador marcou um golo, mas [-] foi, de imediato, anulado pelo árbitro." será, com toda a certeza, o que diremos, não sendo precisa a presença do pronome para sabermos que foi o golo a ser anulado e não o jogador.
} 
“com sujeito, predicado e circunstâncias bem reconhecidas" (Lopes, 1994: 214). Acresce que a relação entre sistema e uso é dinâmica, pois se alimentam e condicionam um ao outro. E se o sistema prevê o uso, é o uso que faz o sistema.

O estudo do uso concorre, aliás, para a descrição da língua como sistema e vice-versa. Na distinção fundadora de Saussure, a langue não é assunto de gente séria e a parole ocupação de menores: “[...] il s'agit là d'une dualité qui doit être pensée ensemble, dans ses articulations, et que, même s'il est légitime de choisir de travailler plutôt en langue ou en discours, il ne l'est pas d'oublier l'autre dimension de la dualité'. (Rabatel, 2017: 52).

Em nosso entender, os avanços inequívocos da Linguística, nas últimas décadas, em Portugal, sairão reforçados se o trabalho sobre a língua e a investigação sobre o discurso se articularem nalgumas interfaces e cada uma das tendências conhecer as propostas da outra.

Os fenómenos linguísticos, sobretudo quando encarados numa perspetiva de uso, revestem-se de grande complexidade e de gradualidade, poucas vezes obedecendo a oposições binárias simplificadoras, pelo menos na área de que nos ocupamos. São bons exemplos deste continuum gradual "cá" e "lá" que vão de valores deícticos estáveis, prototípicos, quando são usados como adverbiais de lugar, até valores cada vez mais subjetivos e modais, como temos procurado mostrar (Duarte, 2010, Duarte \& Marques, 2015 e Marques \& Duarte, 2017 e 2016). Os efeitos de sentido de "um bocado" e "um bocadinho", assunto abaixo referido, também serão mais adequadamente descritos se forem considerados numa estrutura gradativa entre o pólo do muito e o do pouco (cf. Duarte \& Carvalho, 2017).

Os itens linguísticos ganham em ser estudados na sua dupla relação quer com os contextos quer com o género discursivo em que ocorrem e que, com as suas regras sociodiscursivas próprias, lhes impõe restrições linguísticas e textuais. A nosso ver, nem podem mesmo ser adequadamente descritos fora dessa dupla inscrição contextual.

Um mesmo item tem, com frequência, valores e efeitos de sentido vários, conforme os contextos de uso, constatação óbvia mas nem sempre tida em conta, e que é fácil de exemplificar para os Marcadores Discursivos (MD), mas também para os tempos verbais. Veja-se, a título de exemplo, o que escreve Fátima Oliveira (Oliveira, 2015) sobre os usos e valores do imperfeito do indicativo.

Por outro lado, coocorrências de marcas e de indícios que provocam um mesmo efeito de sentido, o concurso de vários elementos linguístico-discursivos para um mesmo fim discursivo justificam que se procure perceber qual a força ilocutória dos enunciados e que objetivos tem o locutor quando os produz. Vale a pena ter em consideração, do ponto de vista da descrição, fenómenos que, em conjunto, contribuem para o mesmo efeito discursivo e estão repartidos por diferentes unidades do discurso (por exemplo: a atenuação da asserção).

A atenção que merecem os usos que os utilizadores fazem da língua não precisa já de defesa, e decorre, quanto a nós, de duas ordens de fatores: uns de tipo teórico e outros de caráter empírico.

\section{1. 2. Razões de tipo teórico}

Concebe-se, hoje, com dificuldade, que se faça pesquisa em Linguística sem partir do estudo de ocorrências atestadas em corpora, para quantificar, analisar e descrever as unidades a investigar. Por outro lado, a ligação dos textos / discursos às suas circunstâncias de produção enunciativa mas também históricas e sociolinguísticas parece ser um facto aceite por uma vasta corrente de opinião em Linguística, abrangendo diferentes tendências (a Pragmática, a Análise de Discurso, a Linguística da Enunciação, a Linguística Textual, o Interacionismo, a Linguística Funcionalista, etc.). Acresce que a consideração essencial dos géneros de textos para uma completa compreensão dos traços linguísticos que neles se plasmam e os caracterizam também é já comummente aceite (na senda do que tem defendido, entre nós Maria Antónia Coutinho e o grupo da Universidade Nova de Lisboa). 
Nada disto é novo. Ora, apesar de algumas destas assunções teóricas se terem tornado, ao longo dos últimos anos, bastante consensuais, muitas das descrições gramaticais que temos para o PE têm por base quase exclusivamente a variedade padrão, um registo escrito e formal, e em muito menor proporção, a língua falada informal e quotidianamente, poucas vezes considerando a variação e só em certas áreas da descrição linguística. Por outro lado, a intuição do investigador continua a ser critério em muitos trabalhos de pesquisa e aceita-se que a maior parte dos exemplos que fornece sejam da sua autoria.

\subsubsection{Razões de tipo empírico}

Algumas reflexões que faremos decorrem do recenseamento de fenómenos do uso, que se verificam num género discursivo concreto, a conversa informal oral, no small talk, cuja relevância para a vida social Bloomaert \& Varis (2015) puseram em evidência.

Numa das Unidades Curriculares por nós lecionadas no Mestrado em Português Língua Segunda / Língua Estrangeira, na Faculdade de Letras da Universidade do Porto ${ }^{5}$, os estudantes têm como tarefa gravar conversas orais informais, respeitando instruções previamente fornecidas, como preencher uma ficha com dados sociolinguísticos e informações sobre a situação enunciativa em que a interação teve lugar, de que depois transcrevem um excerto (ou que transcrevem na íntegra quando se juntam para tratar de uma mesma gravação longa), para isso utilizando as normas Va.Les.Co ${ }^{6}$. Posteriormente, selecionam, do documento, alguns tópicos que consideram importantes para serem tratados em aulas de Português Língua Estrangeira (PLE), procurando explicar que critérios os levaram a considerá-los relevantes nesse contexto. Ora, ao longo de 7 anos de lecionação da Unidade Curricular em causa e de atenção às conversas gravadas, apresentadas e analisadas pelos estudantes, fomos recenseando fenómenos linguístico-discursivos e usos concretos de certos items para os quais nem sempre havia uma descrição satisfatória nas gramáticas ou aos quais até nem havia, por vezes, qualquer tipo de referência.

Feito o levantamento destes elementos invisíveis ou incompletamente tratados na gramática (certos usos do $\operatorname{artigo}^{7}$, p.e.), o passo seguinte consiste em verificar, nos corpora disponíveis, a sua frequência e procurar regularidades e valores de uso. Os fenómenos reportoriados relevam, geralmente, da coconstrução do sentido e são marcas do desejo de cooperar dos enunciadores, que colaboram entre si, como Grice (1975) explicou. No género discursivo selecionado - conversa oral informal -, é facilmente atestável essa coconstrução do sentido, havendo mecanismos variados de modalização do dito, com atenuação ou intensificação de certos segmentos, devidas a estratégias linguístico-discursivas dos locutores, de argumentação que exige ora mitigação ora reforço (Fonseca, 1994). Por meio dessas estratégias, os interlocutores argumentam, responsabilizando-se ora mais ora menos pelo dito, através de mecanismos de "prise en charge" enunciativa (Rabatel, 2017), validando, de forma mais forte ou mais débil, o conteúdo proposicional veiculado pelos seus enunciados, procurando cooperar com o outro, orientá-lo ou convencê-lo. Quando, numa conversa sobre impressoras, o locutor responde à pergunta do interlocutor (amigas, ambas jovens) sobre quanto tempo dura um tinteiro, dizendo "dá p'umas oitocentas páginas", o artigo indefinido tem um uso pragmático e ajuda a modalizar a asserção, diminuindo a responsabilidade do locutor quanto à validação do conteúdo proposicional do seu enunciado, ou seja, quanto à quantidade exata de páginas que um tinteiro permite imprimir ${ }^{8}$. Como

\footnotetext{
${ }^{5}$ Trata-se de Gramática da Comunicação Oral e Escrita.

${ }^{6}$ Adotamos, para a transcrição, as normas Va.Les.Co (Briz, 2002). Como Sandré (2013) afirma, o facto de se utilizar convenções mais ou menos pormenorizadas de transcrição depende dos objetivos do estudo. Dado que estamos a analisar discurso oral plurilogal num registo informal, as normas de Valência parecem-nos adequadas, porque, sendo muito completas, permitem ter em conta uma grande quantidade de variáveis e, sobretudo, as que são pertinentes para análise.

${ }^{7}$ Ver, entretanto, o estudo de Lopes \& Martins (2017) sobre o artigo, que tem em conta questões pragmáticas e situações de uso a que ninguém se ativera até agora.

${ }^{8}$ Gravação de conversa informal disponibilizada pela mestranda Laura Couto, a quem agradeço.
} 
afirma Marques (2014: 96), «Tendo em conta a heterogeneidade e complexidade dos discursos, a modalização tem de ser relacionada com outras vertentes como a construção de tarefas discursivas ou a gestão da relação social e interpessoal."

Ainda no que toca a razões empíricas, na Faculdade de Letras da Universidade do Porto temos feito ${ }^{9}$ levantamentos de perceções de alunos estrangeiros sobre as suas próprias dificuldades de aprendizagem do PLE e é na compreensão e na produção orais (obviamente na interação também) que elas se situam maioritariamente, na opinião dos respondentes ${ }^{10}$. Essas dificuldades decorrem de vários fatores, alguns internos e já estudados, como a redução do vocalismo átono, p.e., e ou questões de tipo fonético-articulatório, mas resultam também do pouco contacto que os alunos têm com a informalidade e o uso oral efetivo. Ora, se não há atenção ao uso no ensino de PLE tal deve-se, em parte, à escassez de descrições, dado que materiais autênticos podem ser encontrados na Internet com alguma facilidade.

Acresce que, ainda no que tange à linguística implicada (designação proposta por Fonseca FI e Fonseca J. 1994, numa versão próxima daquilo a que hoje se chama Educação Linguística) no ensino, agora de Língua Materna, será obviamente incompleta uma visão e uma descrição que tenham apenas em conta o sistema e a norma, porque enferma de reducionismo. A norma padrão não é falada por todos os alunos portugueses. Muitos conhecem apenas outras variedades diatópicas e diastráticas. Também a consideração da variação diafásica é fundamental, dado que a adequação discursiva implica que o Locutor possa fazer escolhas entre registos mais e menos formais, mais e menos vigiados, consoante as circunstâncias enunciativas. Como escreve Fernanda Irene Fonseca (1994: 175), "No âmbito linguístico, tal como no campo político-social, a liberdade é um logro quando associada à pobreza, porque pobreza é sempre sinónimo de impossibilidade de escolha". A variação faz, aliás, parte dos programas de Português do Ensino Secundário ${ }^{11}$. A escola tem, sem margem para discussão, de fazer com que todos os alunos utilizem o português padrão. Mas isso não significa que não esteja atenta a e não descreva os usos orais menos formais e normativizados. Um percurso possível é até partir destes para, alterando, controladamente, as diferentes variáveis do contexto enunciativo, ir adaptando os discursos produzidos em conformidade, como sugere Bertucci (2008). Em "Quelles descriptions de la langue parlée à l'école?", a autora advoga a tese segundo a qual, nos programas de gramática escolar, vale a pena atribuir um espaço às variedades orais faladas pelos alunos. Uma das dificuldades da escola moderna nasceria justamente do fosso entre a língua da escola e as variedades populares orais que os alunos falam, distância de que decorrem insucessos vários. Encarar o ensino da língua numa perspectiva variacionista (Chiss, 2008) pode, segundo Bertucci, ajudar a minorar os problemas. A autora defende a necessidade de a escola se apoiar nas competências linguísticas dos alunos, mesmo que elas pareçam rudimentares, à luz da língua padrão. O professor de Português deveria considerar sempre os contextos em que as formas não estandardizadas são utilizáveis. Pode, assim, levar-se os alunos a dominarem as regularidades da língua a partir da reflexão sobre o seu funcionamento e usos.

Defendemos, portanto, a importância de uma gramática atenta aos usos e às suas descrições, cruciais não apenas para o ensino do Português como Língua Estrangeira e como Língua Materna (tal como Camps, 2009: 203), mas também para o campo da tradução e o dos estudos contrastivos, por exemplo, entre língua românicas ou distintas variedades do português. Algumas diferenças entre PE e Português Brasileiro $(\mathrm{PB})^{12}$, no que concerne ao uso, deveriam ser melhor estudadas, tendo em conta o caráter pluricêntrico da língua portuguesa (Duarte, 2016) e o fluxo recente e crescente, para Portugal, de estudantes nativos de outras

\footnotetext{
${ }^{9}$ Devem-se à minha colega Ângela Carvalho estes levantamentos.

${ }^{10}$ Tivemos em conta os dados do questionário preenchido por 164 alunos de 9 turmas do Curso Anual de Português para Estrangeiros $1^{\circ}$ e $2^{\circ}$ semestres e 1 turma do Curso de Verão de Português para Estrangeiros (nível A1.2, QECR) entre outubro de 2013 e março de 2016 , nas aulas da colega Ângela Carvalho, a quem agradecemos a cedência dos dados.

${ }^{11}$ Ver Buescu et al. (2014).

${ }^{12} \mathrm{E}$ do português falado em África, por exemplo, nos países onde já há descrições em número suficiente.
} 
variedades nacionais. Ana Maria Martins mostrou recentemente (2017), em Mainz ${ }^{13}$, como diferenças entre PB e PE (a ordem de palavras e a posição dos clíticos, no caso) podem ser claramente descritas e problematizadas, com vantagem para a qualidade da descrição, com abonações de corpora e atenção aos contextos.

Um dos pontos de partida para esta reflexão é pois a necessidade de ter em conta o uso real e atestado quer para quem trabalha em tradução quer no ensino, seja de LM seja de LE.

\section{Percurso de investigação experimentado com estudantes. Algumas opções metodológicas e exemplos práticos}

\subsection{Opções metodológicas}

Tendo em conta o que dissemos, justificaremos agora, antes de passarmos à exemplificação, três opções metodológicas para a pesquisa a partir de corpora orais.

Um desses movimentos vai no sentido de observar e analisar as ocorrências e respetivos valores e contextos (sintáticos, semânticos, entonacionais, discursivos, etc.), para as organizar em grupos e as descrever, quantificando a respetiva frequência. Procurar-se-á, assim, "medir" quais os usos mais recorrentes e atribuir pesos relativos aos diferentes valores. Para podermos encontrar regularidades nos usos informais (onde elas, evidentemente, também existem e já por isso podem ser objeto de descrição), temos de analisar um número expressivo de ocorrências. Por exemplo: as 163 ocorrências de "se calhar" no C-Oral-Rom. ("se calhar" que Marques já estudou ${ }^{14}$ ). Olhando apenas para os gráficos gerados no corpusdoportugues, de Davies \& Ferreira, na sua versão mais recente, percebemos já tendências a partir das quais se podem levantar hipóteses a verificar nas ocorrências:

\begin{tabular}{|c|c|c|c|c|c|}
\hline \multicolumn{5}{|c|}{ Corpus do Portuguese: Genre/Historical (i) 国 검 } & \multirow{2}{*}{$\begin{array}{l}\text { (2) EN PT } \\
\text { ACCOUNT }\end{array}$} \\
\hline & SEARC & & & CONTEXT & \\
\hline SECTION & FREQ & SIZE (M) & PERMIL & CUCK FOR CONTEXT (SEE ALL) & \\
\hline 12005 & 0 & 0.6 & 0.00 & & \\
\hline $1300 \mathrm{~s}$ & 0 & 1.3 & 0.00 & & \\
\hline 14005 & 0 & 2.8 & 0.00 & & \\
\hline $1500 s$ & 0 & 4.3 & 0.00 & & \\
\hline $1600 \mathrm{~s}$ & 0 & 3.3 & 0.00 & & \\
\hline $1700 \mathrm{~s}$ & 0 & 2.2 & 0.00 & & \\
\hline $1800 \mathrm{~s}$ & 0 & 9.7 & 0.00 & & \\
\hline $1900 s$ & 307 & 20.3 & 15.15 & 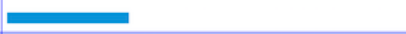 & \\
\hline PORT & 307 & 10.2 & 30.05 & 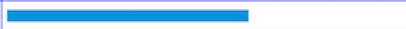 & \\
\hline BRAZ & 0 & 10.0 & 0.00 & & \\
\hline ACAD & 0 & 5.8 & 0.00 & & \\
\hline NEWS & 107 & 6.5 & 16.49 & 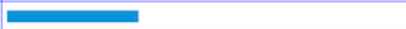 & \\
\hline FICT & 75 & 5.9 & 12.63 & 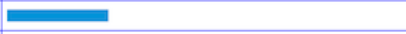 & \\
\hline ORAL & 125 & 2.1 & 60.00 & 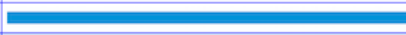 & \\
\hline TOTAL & 921 & & & SEE ALL TOKENS & \\
\hline
\end{tabular}

Gráfico 1. Gráfico gerado pelo subcorpus Genre/Historical para "se calhar"

\footnotetext{
${ }^{13} \mathrm{Ou}$ Mendes et al. num texto de 2015.

14 “O Modalizador Se Calhar: Efeitos De Sentido" (no prelo).
} 
Deste gráfico, ficamos a saber que, no corpus, não há ocorrências antes do século XX, que não existem no PB mas só em PE, que são sobretudo típicas do discurso oral e que não há abonações no discurso académico, porque a expressão não existe em registo formal. $\mathrm{O}$ trabalho de investigação seria para aprofundar e precisar a partir daqui, começando por verificar, se possível em outros corpora, se estas constatações se confirmam.

O subcorpus mais recente, por seu lado, também nos permite esboçar algumas hipóteses.

\begin{tabular}{|c|c|c|c|c|c|}
\hline \multicolumn{5}{|c|}{ Corpus do Português: Web/Dialects (i) 国 } & 2) EN PT \\
\hline & $\mathrm{RCH}$ & & & CONTEXT & ACCOUNT \\
\hline SECTION & FREQ & SIZE (M) & PERMIL & CUCKFOR CONTEXT (SEE ALL) & \\
\hline GENERAL & 5,550 & 453.6 & 12.23 & 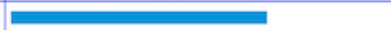 & \\
\hline BLOG & 13,178 & 537.9 & 24.50 & 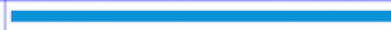 & \\
\hline Brazil & 781 & 558.4 & 1.40 & (口) & \\
\hline Portugal & 15,817 & 270.2 & 58.53 & 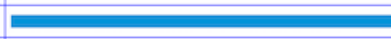 & \\
\hline Angola & 1,435 & 38.4 & 37.42 & 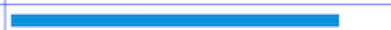 & \\
\hline Mozambique & 695 & 27.9 & 24.93 & 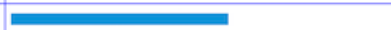 & \\
\hline TOTAL & 18,728 & & & SEE ALL TOKENS & \\
\hline
\end{tabular}

Gráfico 2. Gráfico gerado pelo subcorpus Web/Dialects para "se calhar"

"Se calhar" quase não existe no PB, e os resultados para Angola e Moçambique são mais próximos do $\mathrm{PE}$ do que do $\mathrm{PB}^{15}$. É mais frequente em blogs do que na Internet em geral, o que pode apontar para o seu valor de modalização da asserção, já estudado por Aldina Marques, dado que, sendo os textos de opinião mais frequentes nos blogs, haverá, previsivelmente, mais modalização, nesses textos, do que na Internet em geral.

Mas esta quantificação, se é indicativa de frequências de uso, grandes tendências, direções e percursos diacrónicos das unidades linguísticas, não nos autoriza, geralmente, a tirar tantas conclusões, como quando estudamos, em profundidade, apenas algumas ocorrências. A análise fina, aprofundada e pormenorizada de textos ou sequências onde as unidades a investigar existam permite-nos fazer descobertas sobre os elementos linguísticos em estudo, a partir de regularidades encontradas, dos contextos de uso, das vizinhanças e de testes linguísticos a que podemos submeter os exemplos.

Por fim, há um terceiro movimento que defendemos: aquele que procura analisar e compreender as ocorrências num contexto mais abrangente. Propomos que uma conversa informal, por exemplo, seja estudada desde o início até ao fim, tendo em conta todas as circunstâncias enunciativas conhecidas, para podermos relacionar o valor dessas ocorrências com as suas circunstâncias enunciativas e sociolinguísticas e com os movimentos argumentativos que existem no texto, como, aliás, propõem a Análise Conversacional e outras correntes próximas. Fazem-se descobertas essenciais sobre determinados itens linguístico-discursivos analisando uma unidade texto por inteiro, mesmo que seja extensa, p.e. toda uma conversa, a respetiva situação interlocutiva, a identidade e as relações entre interlocutores, os movimentos argumentativos que atravessam todo o discurso.

O percurso que temos vindo a fazer parte sempre de um corpus de interações orais, de preferência informais. Esses corpora são essenciais para, observando-os de maneira sistemática, referenciarmos fenómenos, traços linguísticos, elementos recorrentes que, depois, procuraremos analisar a partir dos mesmos

\footnotetext{
${ }^{15}$ Esta maior proximidade entre PE e variedades em constituição em Angola e Moçambique é compreensível por razões históricas. Vai no mesmo sentido do estudo de Mendes et al. (2015) e sugere que investigações que abarquem o português falado em diferentes contextos nacionais têm de ser intensificadas.
} 
ou de outros corpora maiores. Os que temos utilizado são os seguintes: o C-ORAL-ROM para o português, o Perfil sociolinguístico da fala bracarense, a nova versão do corpusdoportugues de Davies \& Ferreira, o corpus de conversas informais gravadas e respetivas transcrições que estava a ser construído no Centro de Linguística da Universidade do Porto, as conversas gravadas e transcritas ${ }^{16}$ no âmbito da UC Gramática da Comunicação Oral e Escrita do Mestrado em Português Língua Segunda / Língua Estrangeira da FLUP ${ }^{17}$.

\subsection{Exemplos}

\subsection{1. É assim}

De entre os marcadores discursivos (no sentido de Zorraquino \& Portolés, 1999: 4057) que indicam caminhos para o alocutário calcular as inferências que o locutor pretende que ele faça, selecionamos, pela sua frequência e pela variedade dos seus empregos, o marcador apresentativo "é assim", que se situa entre pausas, em usos que se assemelham ao francês voilà, ao italiano ecco presentes na oralidade, com valores já descritos (De Cesare, 2010, 2011, Zamora Muñoz, 2000, Oppermann-Marsaux, 2006; Porhiel, 2012, Rabatel, 2001). Sobre "assim", destacamos o trabalho de Lopes \& Carapinha (2004) e outro, anterior, de Óscar Lopes (2005 [1985])). Já sobre "é assim" enquanto MD, não encontrámos nenhum estudo. Se muitos exemplos de ecco e voilà podem ser traduzidos por "eis", este "deítico apresentativo", recentemente estudado por Lopes (2017), tradicionalmente considerado um advérbio designativo, ou "palavra denotativa de designação" (Cunha \& Cintra, 1984: 549), mas "eis" é quase inexistente na oralidade, sobretudo em discurso informal. O primeiro valor de "é assim" que vamos referir é o de apresentativo, de focalizador que aponta / sinaliza um argumento ou uma informação que o locutor pretende sublinhar ou afirmar de forma convincente e é típico da oralidade. É assim constrói um "enquadramento discursivo, marcado por uma assertividade forte: o locutor (L) marca a sua adesão ao ponto de vista apresentado pelo enunciador (E)".

(1) - • ((hesitação)) Eu acho que • é assim: no meu caso, foi um bocado um caso à parte. Eu acabei, supostamente, o décimo segundo com dezassete: 07H1D

(2) estavam lá sentadas também é um ato de irresponsabilidade delas, • • porque • • ninguém ((hesitação)) fica... É assim, uma coisa é sentares-te no muro que tem nas bordas, não no meio do separador. 49M1C

No Perfil sociolinguístico da fala bracarense, de onde os exemplos (1) e (2) foram retirados, há 659 ocorrências de é assim, das quais $72 \%$ são "présentatifs" com variados valores. A maior parte das ocorrências (410 VS 63) precedem a asserção sobre a qual o locutor quer atrair a atenção do interlocutor. No final, o marcador tem caráter resumativo e é precedido frequentemente por "pronto" e por "e".

\begin{tabular}{|c|c|c|}
\hline \multicolumn{2}{|c|}{ Apresentativos $72 \%$} & outros $28 \%$ \\
\hline Início & Fim & 186 \\
\hline 410 & 63 & \\
\hline
\end{tabular}

Gráfico 3. é assim no Perfil sociolinguístico da fala bracarense

\footnotetext{
${ }^{16}$ As conversas são gravadas sem conhecimento prévio dos intervenientes, mas com consentimento posterior e deveriam ter cerca de 30 minutos cada. São já mais de uma centena, embora algumas menos extensas doq ue o previsto.
} 
Já no C-ORAL-ROM, há 204 ocorrências de é assim, sendo um pouco menos de metade casos de "présentatifs". O valor deste MD, como se disse, pode ser variado. Funciona, por exemplo como reformulador, numa estrutura do tipo das que vimos em (1) e (2) e da que se segue ou do exemplo (3), em que o locutor corrige uma afirmação anterior ("eu disse que vivia com os meus dois pais"), depois de "é assim".

\section{Hesitação - interrupção / pausa / é assim / reformulação}

(3) não... percebi muito bem porquê. Eu não não não aprecio futebol, mas ela adora futebol. $\bullet O \mathrm{O}$ meu pai, é assim, eu disse que vivia com os meus dois pais, mas o meu pai é emigrante. Ele às vezes é que vem cá a Portugal 54M1D

Nos présentatifs, há um fundo de dêixis (Zafiu, 2015) de que decorre o valor textual de organização discursiva, de introdução remática e valores mais tipicamente interlocutivos de sinalização das sequências mais salientes do discurso. De ambos os valores, também presentes nos usos de "é assim", deriva o de reforço da asserção, ou do comprometimento do Locutor em relação à validação do conteúdo proposicional do que afirma. Outros apresentativos estão a ser estudados por nós, como "imagina", "olha", "repara"18.

\subsubsection{Um bocado / um bocadinho}

Os quantificadores vagos um bocado / um bocadinho aparecem em quase todos os documentos gravados para a UC de que falamos anterioremente, por isso alguns estudantes foram procurar descrições do seu valor e funcionamento. Sendo estudantes do Mestrado em Português Língua segunda / língua estrangeira, têm a tarefa de elencar fenómenos linguístico-discursivos que causam dificuldades de compreensão a alunos estrangeiros e que as descrições das gramáticas não resolvem (cf. Duarte \& Carvalho, 2017).

Trata-se de expressões que poderíamos enquadrar, segundo Channel (1994), no grupo dos quantificadores vagos, atenuadores, mitigadores.

Apresentaremos alguns traços do uso de "um bocado" ["um bocadinho"] a partir das ocorrências encontradas no C-ORAL-ROM. Há 320 de "um bocado" e 217 de "um bocadinho" (que, contrariamente ao que possa parecer, por vezes aponta para uma intensidade mais forte e não para uma intensidade mais fraca do que "um bocado". Esta hipótese parece confirmar-se pelo facto de haver 19 ocorrências de "um bocadinho mais" e só 2 de "um bocadinho menos"). A construção

um bocado de $+\mathrm{N}[+]$ concreto quantificável

aparentemente a única prevista pela maior parte das descrições gramaticais e lexicográficas, corresponde apenas a 3,7\% do total das ocorrências analisadas, ou seja, 29 em 320.

Para além de serem quantificadores vagos, "um bocado" ou "um bocadinho" têm função de atenuação da responsabilidade enunciativa. São, frequentemente, elementos de modalização epistémica, pois indicam "a redução do grau em que o enunciador assume a relação predicativa" (Campos, 1999: 39) ou, nas palavras de Ruzaite, "they minimize the force of verbs and downtone the intensity of adjectives" (Ruzaite, 2007: 94). Contribuem para o funcionamento discursivo eficaz da linguagem elástica ["elastic language"], metáfora que bem transmite a capacidade de ajustamento das palavras às nossas intenções comunicativas: “ [...] we adjust,

\footnotetext{
${ }^{18}$ Comunicação apresentada ao Congresso Discourse Markers in Romance Languages, Lovaina, 2017. De notar, para já, que "repare” é muito mais frequente, como MD, do que "repara", o que pode ter a ver com a relação entre a seleção do MD e o grau de formalidade do discurso. Quanto a "olha", a posição na intervenção determina valores variados, sendo que, só no interior do enunciado, entre pausas, e nunca no seu início, "olha” pode ser considerado apresentativo.
} 
modify, and manipulate our words to accommodate particular discursive needs" (Zhang, 2015: 5) e têm por função mitigar, não só a expressão da quantidade, mas sobretudo a força ilocutória de asserções produzidas pelo locutor, atenuando, na maior parte das ocorrências analisadas, o nível de comprometimento e o grau de intensidade da avaliação crítica do locutor, em atos expressivos, a propósito do estado de coisas do qual fala.

A sua elevada frequência na oralidade pode ser percebida pelos gráficos 4. e 5. gerados no corpusdoportugues de Davies \& Ferreira, em que é visível ainda que as expressões são mais usadas em PE do que no Português do Brasil e têm um uso recente. Estas tendências são mais marcadas ainda no caso de "um bocadinho", como se pode verificar confrontando os dois gráficos ${ }^{19}$.

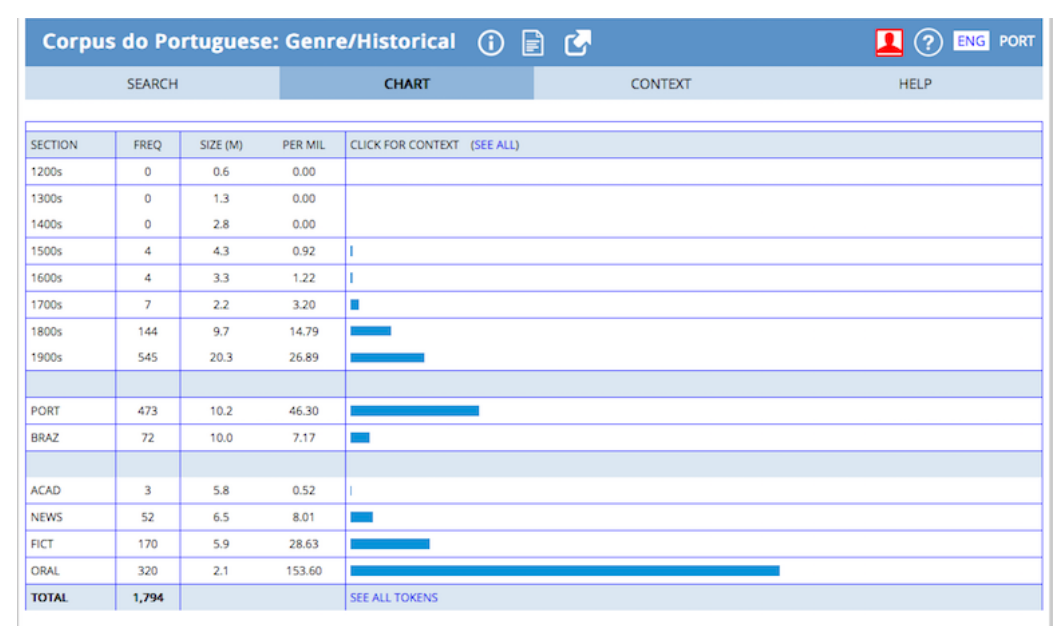

Gráfico 4. Gráfico gerado pelo corpusdoportuguês para "um bocado"

\footnotetext{
${ }^{19}$ Se se pesquisar no novo corpus dos mesmos autores, que inclui também documentos de Angola e Moçambique e é composto por textos da Internet, reforça-se a ideia de que é em Portugal que as duas expressões em causa mais se utilizam e no Brasil que são menos empregues. Nos países africanos referidos usa-se "um bocado" e "um bocadinho" menos do que em Portugal, mas mais do que no Brasil, pelo menos na Internet, o que vai na mesma direção de outros fenómenos já anteriormente referidos e merece posterior investigação.
} 


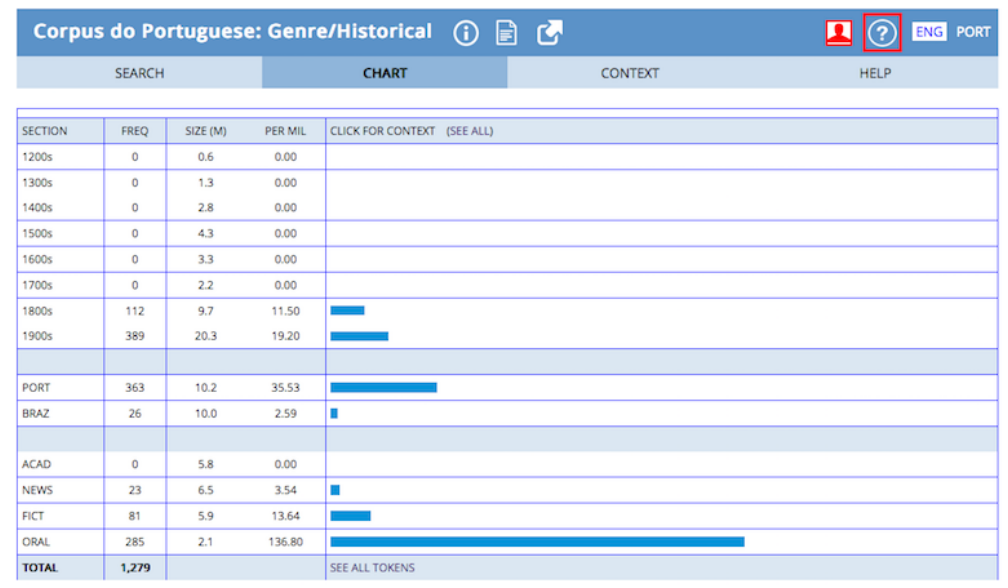

Gráfico 5. Gráfico gerado pelo corpusdoportuguês para "um bocadinho"

Brito (2003: 362) fala de "expressões quantitativas nominais", e acrescenta que elas "[p]odem ser de dois tipos: o primeiro é constituído por formas nominais como pouco, tanto, nadinha, parte, porção, bocado seguidos de de $N$ : exp. de Quant $+d e+N$. Em qualquer destes casos exprime-se uma quantificação vaga que refere "uma parte globalmente considerada."

A autora acrescenta adiante que "[...] nas expressões quantitativas com forma nominal o nome da quantidade tem um estatuto híbrido funcional / lexical: funcional, porque constitui uma forma de quantificação, e lexical, porque há interdependência entre a natureza semântica do primeiro e do segundo nome.

Mas há uma gradação em relação a essa interdependência lexical: ela é fraca com nomes como dúzia, uma vez que se pode usar com qualquer tipo de nome quantificável.” (Brito 2003: 363-364).

No caso das expressões quantitativas nominais vagas analisadas por nós, a interdependência lexical é também fraca, dado que se podem usar com qualquer nome quantificável. Mas, analisando "um bocado" (e "um bocadinho") sobretudo no género conversa oral informal, veremos que entra em outras estruturas que não $d e+N$ e produzem vários efeitos de sentido.

As duas estruturas mais frequentemente encontradas com "um bocado" são as seguintes:

suj + V copulativo [assim] um bocado + [adjetivo (com valor negativo)] ->122 ocorrências; ex. (4)-(5)

suj $+\mathrm{V}$ copulativo [assim] um bocado sem o adjetivo mas com o mesmo valor negativo $\rightarrow 19$ ocorrências; (6)

suj + V copulativo um bocado + outros elementos variados (p.e. SPrep) com valor adjetival (esta cena é um bocado para esquecer; está um bocado em decadência) -> 42 ocorrências. (7)

(4) quer dizer /não na escolha do curso/ pá /porque isso foi uma coisa assim/ um bocado arbitrária /digamos assim // (ppubmn01)

(5) aquilo são dois computadores//é um bocado complicado/ e/ burocrático/ (pfamcv04)

(6) e depois aquilo no fim/ eu acho que dá assim + um é assim um bocado (pfamcv10)

(7) a gente ficou assim um bocado de pé atrás // tipo/ "então o que é que se passa aqui"? (pfamdl09) 
O quantificador vago "diminui a intensidade negativa do adjetivo" ou expressão equivalente (“complicado", "burocrático", “arbitrária”, são adjetivos com conotação negativa; o Sprep «de pé atrás» também), como acontece na maior parte das ocorrências estudadas, estamos perante uma estratégia de autoproteção do locutor. As ocorrências tidas em conta neste grupo são consideradas, de acordo com a nomenclatura gramatical tradicional, locuções adverbiais, pelo menos num dos valores atribuídos a "um bocado" no Dicionário da Academia (2001) ${ }^{20}$, quando este regista, numa das aceções: "loc.adv., um pouco, um tanto $\neq$ MUITO. Estava um bocado abatido.".

A segunda estrutura mais frequente é:

$$
\text { suj + V + um bocado (+ SN) -> } 64 \text { ocorrências }
$$

(8) eh /não sei se nós não teremos um bocado a culpa// nós /e quando eu digo nós /digo os pais /os professores /os educadores /no fundo// porque acho que falta-lhes um bocado isso // [pfamd118]

Como o Dicionário Houaiss (2001) atesta, “um bocado” pode não querer significar (e não significa, na maioria das ocorrências estudadas), pouco, mas, pelo contrário, indicar muito (a entoação é um critério importante para esta decisão; o contexto e a consideração da totalidade da conversa são outros). "Um bocado" situar-se-ia do lado do muito e não do lado do pouco, se imaginarmos uma gradação que vá do pouco ao muito, embora, na segunda aceção que transcrevemos do verbete, "um bocado" já seja sinónimo de pouca quantidade de: "um b. muito, bastante, um tanto (hoje andamos um b.!) (é um b. ousado esse menino!). um b. de 1 grande quantidade ou variedade de (algo) (perderam um b. de dinheiro com aquilo). 2 um pouco de, um pouquinho de (está a fazer um $b$. de frio)".

Como se vê, só o contexto permite decidir, por vezes, se "um bocado" significa pouco ou muito se, usando este quantificador vago, comunicamos muito mas dizemos "um bocado", como forma de mitigar a asserção, como nos exemplos seguintes, em que outros elementos do enunciado marcam uma argumentação que vai no sentido de "um bocado" apontar para o pólo do muito e não do pouco. "Um bocado" está ao serviço, portanto, do (des)comprometimento do locutor em relação ao ato expressivo de crítica, de apreciação negativa que faz: dos bares, dos professores e do ato de beber ácido.

(9) não há/ por exem/ porque alguns bares têm assim um bocado mau ambiente 02H1B

(10) os professores hoje em dia estão a começar a facilitar um bocado. • • Eles não têm mão nos alunos

(11)• Hum. Beber ácido? • • Também é assim um bocado agressivo.

As 3 ocorrências pertencem ao mesmo informante, do corpus de Braga, o que pode indiciar que há usos idiossincráticos e que fazem parte do idioleto pessoal de certos locutores.

A modalização, atenuação ou mitigação de atos assertivos é conseguida, nos enunciados, por uma grande variedade de mecanismos linguístico-discursivos, uma pluralidade de estratégias (Briz, 2013). A constatação de que a maior parte dos exemplos de "um bocado" acima referidos, isto é, os do grupo mais numeroso, coocorrem com verbo copulativo e precedem um adjetivo valorativamente negativo, desempenhando "um bocado" um papel de atenuador da força ilocutória do ato assertivo e do ato expressivo

\footnotetext{
${ }^{20}$ Verificamos ainda a entrada "bocado" e "bocadinho" no Grande Dicionário da Língua Portuguesa da Porto Editora (2004), no Dicionário de Morais (Silva 1987), no Aurélio (Buarque de Holanda Ferreira 1986), no Houaiss (Houaiss 2001), e no Dicionário Etimológico da Língua Portuguesa.
} 
de crítica, é corroborada pelo facto de várias outras estratégias mitigadoras coocorrerem, com frequência, no mesmo enunciado, contribuindo todas, para o mesmo efeito de mitigação da responsabilidade enunciativa do locutor. Como exemplo, podemos ver (12):

(12) pá/ é assim um/ edifício cheio de linhas futuristas/ parece um bocado /assim estilo/ não é bem Schuiten and Peeters/ mas mais ou menos// assim uma coisa (pfammn11)

No exemplo transcrito, "assim" 21 , "parece", "assim estilo", "não é bem”, "mais ou menos" "assim uma coisa" são elementos que têm função idêntica a "um bocado", ou seja, vão no mesmo sentido de mitigação da asserção de cariz apreciativo do locutor, sobre o edifício que quer caracterizar. Como Zhang afirma, escrevendo sobre atenuadores, "They reduce scalar intensity, soften impact, mark probability. Quantifiers expressing a small quantity mitigate more frequently than those expressing a large quantity." (Zhang, 2015: 135).

Duas observações, antes de concluirmos:

1. Embora tenhamos selecionado, para esta apresentação, exemplos isolados do contexto, tivemo-lo em conta na análise, não de todas, mas de muitas ocorrências. Apesar de não o termos feito aqui, defendemos as vantagens de cada conversa ser analisada de forma integral, considerando todas as variáveis em causa, se queremos compreender os movimentos discursivos e argumentativos que as atravessam. Por exemplo: numa conversa gravada ${ }^{22}$ em que um grupo de estudantes de Mestrado estava a preparar uma apresentação em powerpoint, há modalização epistémica, atenuadora de atos assertivos, através do uso frequente quer de "eu acho" (Posio, 2013) quer de "se calhar", para diminuir o desacordo e permitir salvaguardar a face dos outros, de forma aceitável para todos os intervenientes. Em 29 minutos de gravação, há 9 ocorrências de "se calhar" e 14 de "eu acho", que visam modalizar a opinião que se segue, já para não falar de outros elementos de atenuação como os diminutivos ("Queres falar nesta parte também? / porque eu acho que falas muito pouquinho").

2. Uma última vantagem do estudo dos usos em corpora de conversas orais informais é que ilumina, retrospetivamente, a apropriação que a literatura fez desses falares quotidianos e familiares. Ao estudarmos o relato de discurso em corpus oral de conversa informal, verificamos que os verbos dicendi estão frequentemente ausentes (Marques, 2015, Duarte \& Silva no prelo) e recordamo-nos dos romances de EQ, compreendendo melhor por que motivo aqueles eram, para o escritor, "os detestados verbos dicendi", como escreveu Guerra da Cal (1981). Em discurso oral informal, o DD é as mais das vezes introduzido sem qualquer verbo de palavra, identificando-se apenas o locutor ao qual são atribuídas as palavras relatadas, com a intenção de dramatizar e tornar mais vivo o discurso. Obviamente que há sempre, do ponto de vista da entoação, uma mudança de tom, no momento em que se passa para as palavras que são relatadas ou atribuídas ao locutor relatado. Com frequência, o segmento introdutor de relato resume-se a "e eu" / "e ela" / "e a mãe", "e vai ela", ou "vai ele assim", "vira-se ele", "e a mãe do tipo", etc.

(13) E eu olha 'tás a ensinar ensina-me tam'ém a mim.

(14)... tu fazias e eu ahh muito bem que giro como é que isso se faz isso? E a mãe do género eh, quié isso?

(15) e ela como é qué? Como é qué?

(16) Foi ontem à tarde. eu estava em casa batem-me à porta e eu quem é? e diz ele é deus e eu quem?! e lá de fora é deus pá! o criador de tudo isto e tale.

\footnotetext{
${ }^{21}$ Para os valores de "assim”, ver Lopes e Carapinha (2004).

${ }^{22}$ Faz parte do corpus que estava em construção no CLUP.
} 
(17) e eu sim senhor, sim senhor... bom, o senhor fique aqui na sala a ber televisão qu'eu bou a mais a minha mulher fazer o lanche. ${ }^{23}$

Um pequeno aparte para chamar a atenção para o exemplo (14) "e a mãe, do género" + DD. Como se vê pelo uso de "do género", e também em ocorrências com "e ele, tipo:”, o relator tem consciência de que, embora vá sinalizar, pela alteração da voz, que vai relatar palavras atribuídas à mãe, essas palavras não são uma reprodução fiel do discurso real que a mãe produziu, como afirma a gramática tradicional e as gramáticas escolares e os manuais repetem. A mãe proferiu palavras "do género", "tipo", diríamos nós, "como" as que vão ser recriadas pelo relator, como se fossem as que a mãe realmente produziu.

\section{Considerações finais}

Procuramos mostrar a necessidade de ter em conta "[...] a realização discursiva efectiva, onde intervêm factores de extrema heterogeneidade" (Fonseca, J. 1994: 96), de descrever os usos dos elementos linguísticodiscursivos mais frequentes em conversas espontâneas e menos referidos nas gramáticas, em PE. Para essa tarefa, haverá que poder utilizar corpora em que se recolham e transcrevam documentos desse género discursivo concreto, porque ela exige a análise de dados empíricos que permitam retirar regularidades e fazer generalizações. Essas descrições do uso fazem falta para o ensino do português e para os investigadores que pretendem realizar estudos contrastivos (entre línguas românicas, como propõe Pop (2012: 92), ou entre PB e $\mathrm{PE}$, para só falarmos destas duas variedades nacionais de português ${ }^{24}$ ). Para esta comparação, seria preciso termos descrições das particularidades de cada língua, tal como são usadas pelos locutores reais.

Há por estudar um conjunto de fenómenos linguísticos e discursivos que não foram descritos pelas gramáticas portuguesas, quase integralmente feitas com base na descrição da norma padrão e da língua escrita e muito raramente tendo em conta o uso, na oralidade, sobretudo na oralidade informal. Ora, a língua em uso também é língua.

\section{Referências}

Batalha, Joana (2017) Relações entre conhecimento explícito da língua e a competência de leitura. Dissertação de doutoramento. Universidade Nova de Lisboa.

Bertucci, Marie-Madeleine (2008) Quelles descriptions de la langue parlé e à l'école? Le Français Aujourd'hui, Descriptions de la langue et enseignement, $\mathrm{n}^{\circ} 162$, pp. 59-70.

Blommaert, Jan \& Varis, Piia (2015) The importance of unimportante language. Multilingual Margins, Bellville, v.2, n.1, pp. 4-9.

Brito, Ana Maria (2003) Quantificadores e expressões quantitativas. In Maria Helena Mira Mateus et al. (eds.), Gramática da Língua Portuguesa. Lisboa: Editorial Caminho, pp. 355-365.

Briz, Antonio (2013) A atenuação e os atenuadores: estratégias e táticas. Linha d'Água, São Paulo, v.26, n.2, pp. 281-314.

Briz, Antonio \& Val.Es.Co (2002) Corpus de conversaciones coloquiales. Madrid: Arco-Libros.

\footnotetext{
${ }^{23}$ Os três primeiros exemplos foram gravados e transcritos pela ex-estudante de Gramática da comunicação oral e escrita do Mestrado em Português L2/LE, Ana Salomé Teixeira, no ano letivo de 2011-12. Os dois seguintes pelo então estudante António Rafael Freitas, do programa "Mixórdia de temáticas" da Rádio Comercial, do dia 8 de maio de 2012. Ambos usaram as normas de transcrição REDIP (Ramilo e Freitas, 2002). Agradeço a ambos os exemplos.

${ }^{24}$ Desejavelmente, também para o português falado nos outros países da Comunidade de Países de Língua Portuguesa.
} 
Buescu, Helena et al. (2014) Programas e Metas Curriculares de Português. Ensino Secundário. Ministério da Educação e Ciência.

Campos, Henriqueta (1999) Para uma distinção formal entre operações de modalização: sobremodalização e remodalização. Actas do VI Encontro da Associação Portuguesa de Linguística, Porto: Universidade do Porto, pp. 31-41.

Camps, Anna (2009) Actividad metalingüística y aprendizaje de la gramática: hacia un modelo de enseñanza basado en la actividad reflexiva. Cultura y Educación, 21 (2), pp. 199-213.

Channell, Joanna (1994) Vague Language. Oxford: Oxford University Press.

Chiss, Jean-Louis (2008) Postface: langue(s) et grammaire(s). Le français aujourd'hui, n 162, pp. 115-117. DOI 10.3917/lfa.162.0115

Carreira, Maria Helena (Org.) (2012) Les rapports entre l'oral et l'écrit dans les langues romanes. Paris: Université Paris 8.

Cunha, Celso \& Cintra, L. F. Lindley (1984) Nova Gramática do Português Contemporâneo. Porto, Figueirinhas.

De Cesare, Anna-Maria (2010) Gli impieghi di 'ecco' nel parlato conversazionale e nello scritto giornalistico. In Ferrari, Angela / De Cesare, Anna-Maria. Il parlato nella scrittura italiana odierna. Riflessioni in prospettiva testuale. Bern, Berlin, Bruxelles, Frankfurt am Main, New York, Oxford, Wien, pp. 105147.

De Cesare, Anna-Maria (2011) L'italien ecco et les français voici, voilà. Regards croisés sur leurs emplois dans les textes écrits. Langages, 184, pp. 51-67.

Duarte, Isabel Margarida (2016) Português, Língua Pluricêntrica: Que Português Ensinar Em Aulas De Língua Estrangeira?. In Andrade, C.; Micheletti, G.; Seara, I. (Org.) Memória Discurso e Tecnologia. São Paulo: Terracota Editora, pp. 217-236.

Duarte, Isabel Margarida (2010) La dimension modale de cá et lá en portugais. Studii și Cercetări Lingvistice, vol. LX, pp. 179-195.

Duarte, Isabel Margarida \& Marques, Aldina (2015) Acta Semiotica et Lingvistica, v.20, n², pp. 115-128. http://periodicos.ufpb.br/index.php/actas/article/viewFile/28020/15037

Duarte, Isabel Margarida \& Carvalho, Ângela (2017) Conversa informal e linguagem vaga - "um bocado" e "um bocadinho": contributos para o ensino do Português Língua Estrangeira. Portuguese Language Journal, 11, pp. 146-164.

Duarte, Isabel Margarida \& Carvalho, Ângela (2016) Ensino de PLE, conversa oral informal e vagueza algumas sugestões. In Gonçalves, Luís (ed.). O ensino do Português como Língua Estrangeira: reflexões sobre a prática pedagógica, Roosevelt, NJ: American Organization of Teachers of Portuguese, pp. 89103.

Duarte, Isabel Margarida \& Silva, Fátima. Revisitação do discurso relatado no ensino- aprendizagem do PLE. In Ciama, A.; Teletin, A. (Org.) Tempo, espaço e identidade na cultura portuguesa: desafios e perspetivas. București: Ed. Universităţii din București, [20-]. 2 v. No prelo.

Fernanda, Fernanda Irene (1994) A urgência de uma pedagogia da escrita. In Gramática e Pragmática, Estudos de Linguística Geral e de Linguística Aplicada ao Ensino do Português. Porto: Porto Editora, pp. 147-176.

Fonseca, Joaquim (1992) Heterogeneidade na Língua e no Discurso. In Linguística e Texto I Discurso. Lisboa: ME/ICALP, pp. 249-292.

Fonseca, Joaquim (1994) Pragmática linguística: Introdução, teoria e descrição do português. Porto: Porto Editora.

Grice, Henri Paul (1975) Logic and Conversation. Syntax and Semantics, Vol. 3, pp. 41-58. 
Guerra da Cal, Ernesto (1981) Língua e Estilo de Eça de Queiroz. Coimbra: Almedina.

Johnen, Thomas (2012) La représentation écrite de l'oral dans des méthodes de Portugais Langue Étrangère. In Carreira, Maria Helena (Org.) Les rapports entre l'oral et l'écrit dans les langues romanes. Vincennes: Université Paris 8. pp. 307-328.

Lopes, Ana Cristina (2017) Eis: um dêitico apresentativo? Comunicação ao colóquio de Homenagem a Óscar Lopes, Porto, Faculdade de Letras.

Lopes, Ana Cristina \& Martins, Cristina (2017) Para o ensino dos artigos em PLE: por onde começar? Portuguese Language Journal, 11. pp. 165-189.

Lopes, Ana Cristina \& Carapinha, Conceição (2004) Contributos para uma análise semântico-pragmática das construções com assim. Cadernos de Linguística, 5, pp. 57-80.

Lopes, Óscar (2005) Algumas peculiaridades do Português, e especialmente do português europeu, que importam à teoria da semântica linguística universal. Entre a palavra e o discurso. Estudos de Linguística 1997-1993. Porto, Campo das Letras, pp. 15-40.

Lopes, Óscar (1994) A Busca de Sentido: Questões de Literatura Portuguesa. Lisboa: Caminho

Marques, Aldina. O modalizador se calhar: efeitos de sentido. Estudos Linguísticos / Linguistic Studies. (no prelo)

Marques, Aldina (2015) O discurso relatado em interações orais coloquiais. In Marques, Aldina; Rei, Xosé Manuel S. Revista Galega de Filoloxia: monografia 10: novas perspetivas linguísticas no espaço galegoportuguês. Coruña: Consorcio Editorial Galego, pp. 89-109.

Marques, Aldina \& Duarte, Isabel Margarida. Funções discursivas das construções com a partícula LÁ. Colóquio dos 40 anos do Centro de Linguística da Universidade do Porto. (no prelo)

Marques, Aldina \& Duarte, Isabel Margarida (2017) Lá, atenuador em interações informais do Português Europeu. Studia Universitatis Babeș-Bolyai. Philologia LXII, 4, pp. 17-34. DOI:10.24193/subbphilo.2017.4.02

Martins, Ana Maria (2017) A ordem das palavras em variedades nacionais do português. Conferência Plenária no $12^{\circ}$ Congresso alemão de Lusitanistas - Polifonia: uma língua, muitas vozes, Universidade Johannes Gutenberg, Mainz.

Martin Zorraquino, María Antonia \& Portoles Lazaro, José (1999) Los marcadores del discurso. In Bosque, Ignacio; Demonte, Violeta (Org.) Gramática descriptiva de la lengua española. Madrid: Real Academia Española, pp. 4050-4213.

Matos, Sérgio (2008) A cultura pela língua: algumas reflexões sobre pragmática (inter)cultural e ensinoaprendizagem de língua não materna. In Duarte, Isabel Margarida; Oliveira, Fátima (Org.) $O$ fascínio da linguagem: actas do colóquio de Homenagem a Fernanda Irene Fonseca. Porto: Universidade do Porto, Faculdade de Letras e Centro de Linguística, pp. 391-406.

Mendes, Amália et al. (2015) Pronominal constructions and subject indetermination in varieties of Portuguese. In Muhr Rudolf; Marley, Dawn (orgs.) Pluricentric Languages: New Perspectives in Theory and Description, Frankfurt am Main, Berlin, Bern, Bruxelles, New York, Oxford, Wien, Peter Lang, pp. 109-125.

Neves, Maria Helena (2000) Gramática de Usos do Português. São Paulo: UNESP. $2^{\mathrm{a}}$ ed.

Oliveira, Fátima (2015) O Imperfeito e o tempo dos indivíduos. Estudos de Semântica. Universidade do Porto, CLUP, pp. 8-24.

Oppermann-Marsaux, Evelyne (2006) Les origines du présentatif voici/voilà et son évolution jusqu'à la fin du XVIe siècle. Langue Françise 149, pp. 77-91.

Posio, Pekka (2014) Subject expression in grammaticalizing constructions: the case of creo and acho 'I think' in Spanish and Portuguese. Journal of Pragmatics 63. pp. 5-18.

Porhiel, Sylvie (2012) The presentative voici/voila - Towards a pragmatic definition. Journal of Pragmatics 44 , pp. 435-452. 
Pop, Liana (2012) De l'oral à l'écrit: articulation micro et macro-syntaxique. In Carreira, M. H. A. (Org.) Les rapports entre l'oral et l'écrit dans les langues romanes. Vincennes: Université Paris 8, pp. 75-93.

Rabatel, Alain (2017) Pour une lecture linguistique et critique des médias. Empathie, éthique, point(s) de vue. Limoges: Lambert-Lucas.

Rabatel, Alain (2001) Valeurs énonciative et représentative des 'présentatifs' C'EST, IL Y A,VOICI/VOILA: effet point de vue et argumentativité indirecte du récit. Revue de Sémantique et Pragmatique, pp. 43-74.

Ramilo, Maria Celeste \& Freitas, Tiago (2002) A linguística e a linguagem dos média em Portugal: descrição do projecto REDIP. Disponível em http://www.iltec.pt/pdf/wpapers/2002-redip-redip.pdf [consultado em 27 de maio de 2018).

Raposo, Eduardo Paiva et al. (2013) Gramática do Português. Lisboa: Fundação Calouste Gulbenkian,

Ruzaitè, Jūratė (2007) Vague Language in Educational Settings: Quantifiers and Approximators in British and American English. Frankfurt am Main: Peter Lang.

Sandre, Marion (2013) Analyser les discours oraux: approche pluridisciplinaire. Paris: Armand Colin.

Zafiu, Rodica (2015) Presentative markers in old romanian: Divergent Changes in the syntactic and pragmatic uses of adică and iată. In Gabriela Pană Dindelegan, Rodica Zafiu, Adina Dragomirescu (ed) Diachronic Variation in Romanian.Cambrige Scholars Publishing, pp. 426-453.

Zamora Muñoz, Pablo (2000) Usos de ecco en el italiano hablado contemporáneo. Cuadernos de Filología Italiana, $\mathrm{n}^{\mathrm{o}}$ extraordinario, pp. 949-966.

Zhang, Grace (2015) Elastic Language. How and Why we Stretch our Words. Cambridge: Cambridge University Press.

\section{Dicionários}

Buarque de Holanda, Aurélio (1986) Novo dicionário da língua portuguesa. Rio de Janeiro: Nova Fronteira.

Dicionário da Língua Portuguesa Contemporânea da Academia das Ciências de Lisboa (2001) Lisboa: Verbo.

Grande Dicionário Língua Portuguesa (2004) Porto: Porto Editora.

Houaiss, Antônio (org.) (2001) Grande Dicionário Houaiss da Língua Portuguesa. Rio de Janeiro: Editora Objetiva.

Machado, João Pedro (1977) Dicionário Etimológico da Língua Portuguesa. $3^{\mathrm{a}}$ ed. Lisboa: Livros Horizonte.

Silva, António de Morais (1987) Novo dicionário compacto da língua portuguesa. Ed. compacta segundo a $10^{\mathrm{a}}$. ed. rev., muito aumentada e actualizada. Lisboa: Confluência.

\section{Corpora}

CETEMpublico http://www.linguateca.pt/cetempublico/

CRPC: Corpus de Referência do Português Contemporêno http://www.clul.ul.pt/pt/recursos/183-referencecorpus-of contemporary-portuguese-Corpus

Davies, Mark and Michael Ferreira. (2006-) Corpus do Português: 45 million words, 1300s-1900s. Available online at http://www.corpusdoportugues.org.

Perfil sociolinguístico da Fala bracarense.

https://sites.google.com/site/projectofalabracarense.

C-Oral-Rom 